\title{
Construction of the structural equation model of badminton players' variable direction ability and its enlightenment to sports training
}

\author{
Qinghe Li ${ }^{1,2}$, Haiyong Ding ${ }^{1}$ \\ ${ }^{1}$ School of Physical Education and Training, Shanghai University of Sport, Shanghai, China; ${ }^{2}$ Department of Basic Education, Jiangsu Shipping \\ College, Nantong, China \\ Contributions: (I) Conception and design: All authors; (II) Administrative support: H Ding; (III) Provision of study materials or patients: All authors; \\ (IV) Collection and assembly of data: All authors; (V) Data analysis and interpretation: All authors; (VI) Manuscript writing: All authors; (VII) Final \\ approval of manuscript: All authors. \\ Correspondence to: Haiyong Ding. School of Physical Education and Training, Shanghai University of Sport, 200 Hengren Road, Yangpu District, \\ Shanghai 200438, China. Email: 1074145584@qq.com.
}

Backgroundt With the continuous development of modern badminton, higher requirements were put
forward for the comprehensive quality of athletes. Studies show that players' ability of changing direction
play an important role in badminton competition. In the present study, the SpeedCourt test system was used
to study factors of badminton players' variable direction ability.
Methods: A total of 101 badminton players were included. The SpeedCourt test system was used to test
the variable direction ability of players through three categories: speed chase, jump and reaction. Principal
component analysis and moment structure analysis were used to analyze the test data.
Results: Four influencing factors were found of badminton players' variable direction ability; these are
moving speed, coordination, reaction, and explosive force. The structural equation model of variable
direction ability and the 4 influencing factors fit well with the measured data. The correlation between
variable direction ability and coordination was the highest ( $\mathrm{r}=0.91)$, followed by moving speed (0.86),
reaction (r=0.81), and lower extremity explosive force $(\mathrm{r}=0.79)$.

Conclusions: This paper demonstrates the structural equation model of badminton players' ability to change direction from an empirical point of view, which lays a foundation for the study of badminton players' agility and provides a reference for sports practice.

Keywords: Badminton player; variable direction ability; structural equation model; factor analysis

Submitted Feb 04, 2021. Accepted for publication Apr 17, 2021.

doi: 10.21037/apm-21-644

View this article at: http://dx.doi.org/10.21037/apm-21-644

\section{Introduction}

Badminton players need to have special physical quality, including speed quality, strength quality, sensitive quality and so on (1). In addition to the competition of traditional sports skills and tactics, the competition for specific qualities of athletes is fiercer than ever before. With the continuous development of modern badminton, higher requirements were put forward for the comprehensive quality of athletes. Therefore, it is important to improve the "sensitive quality" of badminton players. The sensitive quality of badminton players plays an important role in the process of attack and defense conversion, and the level of sensitive quality determines the victory or defeat of the game to a great extent.

Zhao et al. defines sensitive quality as the ability of the body to feel stimuli in a particular exercise scene, and to quickly change direction or change action as needed (2). The ability to change direction is the embodiment of the 
high and low sensitivity quality. An athlete with good sensitivity must have excellent ability to change direction. Moreover, in the badminton sport, there is a lot of urgent stops. Athletes are changing the direction of body movement all the time. The ability of changing direction has a great impact on sports performance. Phomsoupha et al. found that the ability to predict and rapid change the direction of body directly affect the performance of badminton players in the field, which play a key role in determining the success or failure of the game (3). In their study, Meir et al. found that the ability to sprint and change direction during sprint is a decisive factor of sports performance, and represents athletes' sensitive quality (4).

Therefore, the aim of the present study was to analyze badminton players' ability to change direction. We found that 4 influencing factors contribute to the variable direction ability of badminton players; these are movement speed, coordination, reaction, and explosive force. By using the SpeedCourt test system (GlobalSpeed, Hemsbach, Germany) as a testing tool, we established the structural equation of badminton players' ability to change direction, and provide a reference for badminton players' training and research of special quality in the future.

We present the following article in accordance with the MDAR reporting checklist (available at http://dx.doi. org/10.21037/apm-21-644).

\section{Methods}

\section{Test subjects}

A total of 101 undergraduate students from Shanghai Institute of Physical Education and Training were selected as the test subjects. All test subjects are badminton players above three levels, according to Chinese badminton sports level rating standard. All human trials have been approved by Shanghai Institute of Physical Education and Training (No. 2017047). All procedures performed in this study involving human participants were in accordance with the Declaration of Helsinki (as revised in 2013). Informed consent was taken from all the patients.

\section{Research method}

We have consulted web of science databases related to sensitivity and ability to change direction.

The SpeedCourt test system was used to test the badminton players' ability to change direction. The system is designed for testing and training speed, sensitivity, coordination, variable direction change, and cognition, and has the most advanced speed-sensitive training programs. It can design different testing and training programs for different sports. Reliability and validity of the system have been proofed (5). There are 3 categories related to the ability of athletes to change direction in the SpeedCourt test system, as shown in Table 1.

\section{Statistical analysis}

Excel was used to input SpeedCourt test data; SPSS version 25.0 (IBM, Armonk, NY, USA) was to the factor analysis of the data and calculate the factors related to badminton players' variable direction ability; and AMOS (IBM, Armonk, NY, USA) was used to analyze the path of structure equation of badminton players' ability to change direction, and fitting degree test was carried out with the measured data.

\section{Results}

\section{Factor analysis of badminton players' ability to change direction}

In Kaiser-Meyer-Olkin (KMO) Measure of Sampling Adequacy, KMO values between 0 and 1 (6). In general, a $\mathrm{KMO}$ value $<0.5$ is not suitable for factor analysis. The number KMO of this research is 0.737 , indicating the existence of common factors among variables. In addition, in our sample data, the approximate $\chi^{2}$-value of Bartlett's test of sphericity was 875.760 , and $\mathrm{P}=0.000$, so the original hypothesis can be rejected and it also indicated the existence of common factors between the correlation matrices of the overall sample; therefore, this research was suitable for factor analysis (Table 2).

\section{Calculation of cumulative contribution}

Using the factor analysis, 4 main factors were found after rotation, and the cumulative contribution rate of the 4 main factors reached $78.331 \%$, which indicated that these factors could explain $78.331 \%$ of the component factors of badminton players' variable direction ability. Therefore, these factors can explain the badminton players' ability to change direction (Table 3). 
Table 1 Test index of variable direction ability of badminton players

\begin{tabular}{|c|c|c|}
\hline Evaluation elements & Test category & Indicator name \\
\hline \multirow{9}{*}{ Reversing ability } & & Number of correct contacts \\
\hline & & Number of times the left foot touches the pad correctly \\
\hline & & Number of times the right foot touches the pad correctly \\
\hline & & Average turning time of left foot \\
\hline & & Average turning time of right foot \\
\hline & Jump & Vertical jump height \\
\hline & & Average flight time of legs \\
\hline & & Average reaction time of left foot \\
\hline & & Average reaction time of right foot \\
\hline
\end{tabular}

Test time for all 3 categories was $30 \mathrm{~s}$.

Table 2 Results of Kaiser-Meyer-Olkin (KMO) value and Bartlett's test of sphericity

\begin{tabular}{lccc}
\hline \multirow{2}{*}{ KMO sampling appropriate quantity } & \multicolumn{3}{c}{ Bartlett's test of sphericity } \\
\cline { 2 - 4 } & Approximate chi-square & Degree of freedom & P value \\
\hline 0.737 & 875.76 & 66 & 0.000 \\
\hline
\end{tabular}

Table 3 Cumulative contribution rate of variance

\begin{tabular}{|c|c|c|c|c|c|}
\hline \multicolumn{3}{|c|}{ Initial eigenvalue } & \multicolumn{3}{|c|}{ Ingest the sum of squares of the load } \\
\hline Total & Variance (\%) & Cumulative percentage & Total & Variance $(\%)$ & Cumulative percentage \\
\hline 2.544 & 21.204 & 52.781 & 2.544 & 21.204 & 52.781 \\
\hline 1.639 & 13.662 & 66.443 & 1.639 & 13.662 & 66.443 \\
\hline
\end{tabular}

\section{Main factors of badminton players' ability to change direction}

Because the initial factor load is complex and it is difficult to explain the rationality of the variable, it is necessary to rotate the initial factor. Initial factor is the interdependent common part of the variable after factor analysis, which represents the basic data structure of the initial variable. The initial factor can only be rotated to highlight the variables it represents.
In the present study, the original factor was rotated by the quartimax method, and the factor was differentiated after rotation, which is beneficial for classifiying and explaining the factor reasonably. According to the factor analysis statistical principle, the common factor can be extracted if the characteristic value after rotation is $>1$ and the factor load is $>0.6$; therefore, 4 common factors were used in the present study. As seen in Table 4, factor 1 had a higher load on the variable distance, the number of times feet touched 
Table 4 Cut-off load matrix after rotation

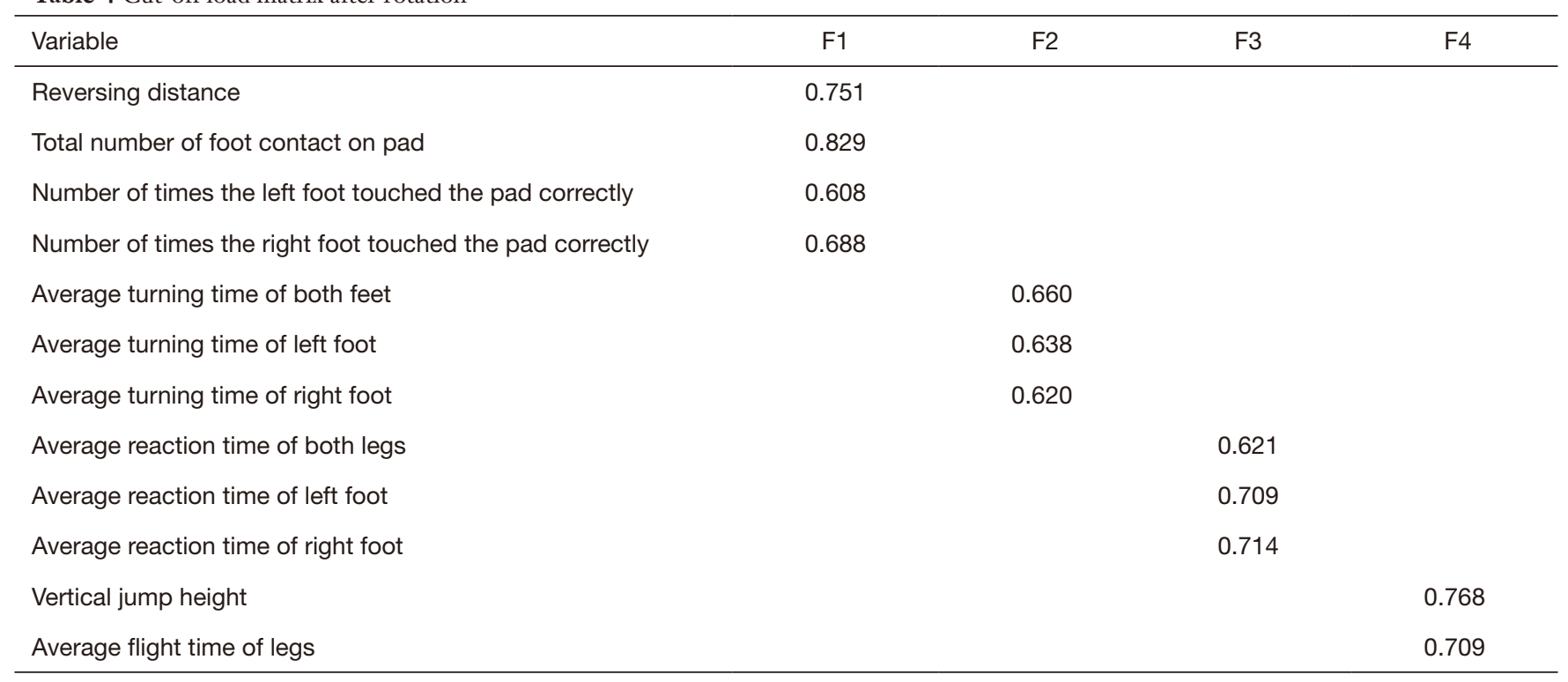

the pad, the number of times the left foot touched the pad, and the number of times the right foot touched pad. These 4 indexes all have an impact on the distance of the athletes running in $30 \mathrm{~s}$. As the time was determined, the difference was the distance of the athletes' movement, which was mainly caused by the difference in the speed of athletes. Therefore, factor 1 (F1) can be named as the moving speed factor. Factor 2 (F2) were higher in terms of the mean turning time of feet, the mean turning time of the left foot, and the mean turning time of the right foot, while the 3 index variables involved leg turning time. The length of leg turning time was highly correlated with the coordination of lower limbs; therefore, $\mathrm{F} 2$ can be named as the coordination factor. The factor loads with relatively high factor 3 include the average response time of both legs, the average response time of the right leg and the average response time of the left leg. Therefore, F3 can be named as the response ability factor. Factor 4 (F4) was closely related to the vertical jump height and the average flight time of both legs, which are both the manifestation of explosive power of legs. Athletes with stronger explosive power of legs can achieve higher vertical jump height and longer flight time (7); therefore, F4 can be named as the explosive force factor (Table 4).

\section{Construction of structural equation of variable direction ability of badminton players}

According to the factor analysis, 4 common factors related to the variable direction ability of badminton players were found; these were moving speed, coordination, reaction, and explosive force. These factors were all first-order latent variable factors. According to the principle established by the structural equation model, there was also a secondorder latent variable above the first-order latent variable, that is, variable direction ability was determined using AMOS 24.0 software, following the principle established by the structural equation. The path diagram of the structural equation model was established, as shown in Figure 1. Using AMOS statistical software, the linear model path analysis is carried out for the data of the four factors, and the correlation coefficient is obtained according to Figure 1, the correlation coefficient between variable direction ability and coordination was highest, reaching 0.91 , indicating that the coordination of badminton players has the greatest influence on variable direction ability. The correlation coefficients between the 4 main factors and the first-order latent variables of variable direction ability were $0.86,0.91$, 0.81 , and 0.79 , respectively. The purpose of the degree of fit test is to test the degree of coincidence between the structural equation model established and the actual data.

The test criteria of the overall fitness of Wu's structural equation model were compared with the fitness values of the present study (8). As showed in Table 5, in this study, $\mathrm{P}=3.15>0.05$ and $\chi^{2} / \mathrm{df}=1.239<2.00$, indicating that the results were not statistically significance. The nihilistic hypothesis was accepted, and all other values of absolute 


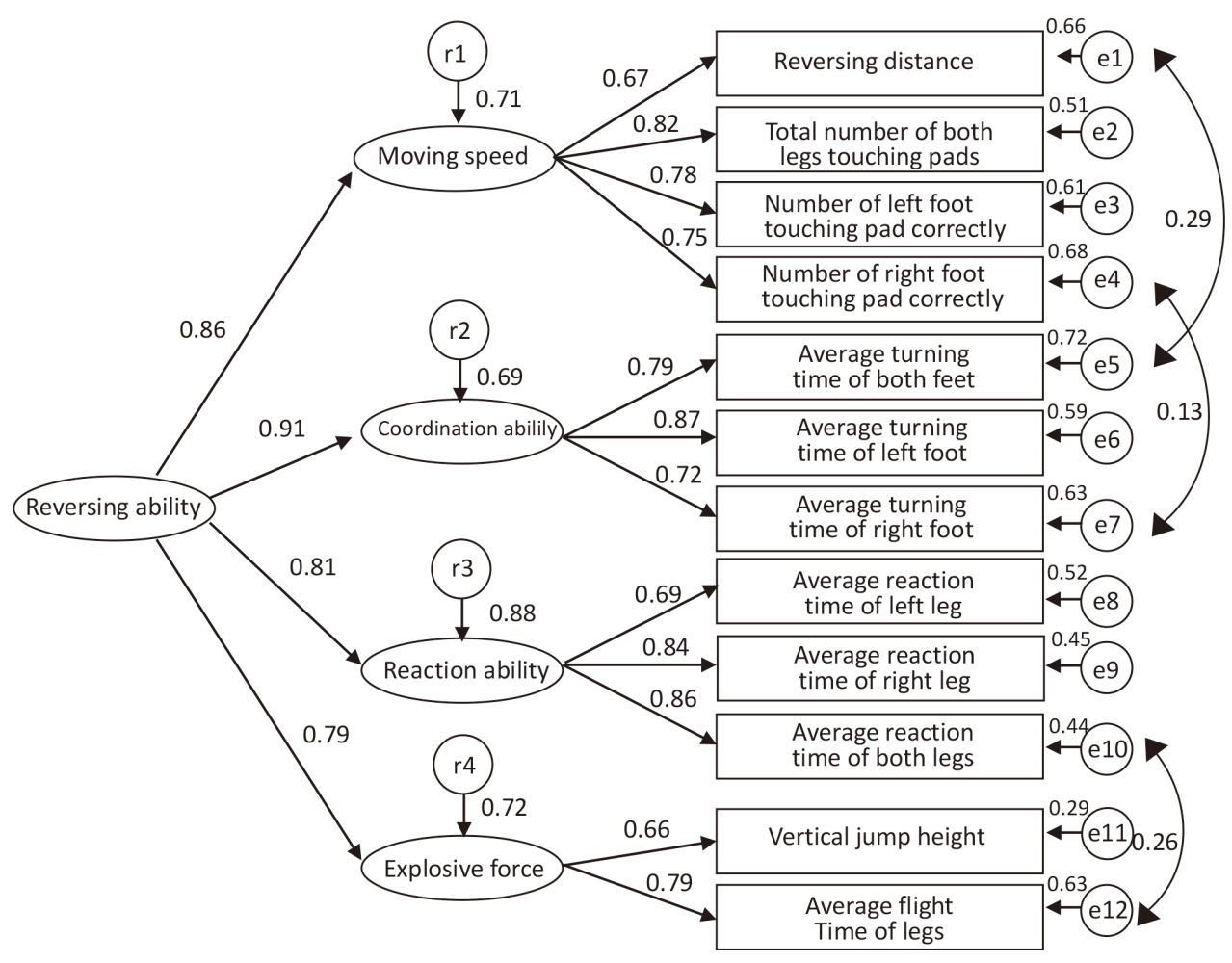

Figure 1 Structural equation path model diagram of badminton players' reversing ability.

fitness, value-added fitness, and parsimonious fitness met the critical criteria of fitness. The structural equation model of the sensitive quality of badminton players established in the present study was consistent and fit well with the actual data. Our model has good conceptual reliability and can be used as a reference for the training of sensitivity in badminton sports.

\section{Discussion}

\section{Mobile speed training is a necessary condition for badminton players}

Moving speed is important in sport. A skillful athlete without moving speed is difficult to become an outstanding athlete. There is a lot of urgent stops in the badminton sport. Without a good moving speed, the players' technical and tactical level can not be brought into play. In their study, Sung et al. used a tracking experiment to analyze 50 badminton players. They found that there were significant differences in the accuracy of lower limb movement speed in terms of batting; the faster the lower limb movement speed, the higher the accuracy of batting in the game (9).
Abdul Hamza et al.'s research on the relationship between the performance of badminton players in the Iraqi National Youth Team and their level of physical fitness found that the better performance as positively related to the athletes' movement speed and explosive force of the lower limbs (10). Salah et al.'s research on influencing factors of hitting accuracy of women's badminton players found that the most important reason for players to make mistakes in the game was that their moves did not reach the designated position. In the competition, when fatigue occurs, the moving speed of legs will be affected first, which will lead to the decrease of the balance ability of players. So, in the process of daily physical quality training, to increase the lower limb movement speed and lower limb endurance training, so that we can make up for the fatigue phenomenon lose points because the pace is not in place appear (11).

Chen found that the fast and slow conversion of badminton players will directly affect the effect of attack and defense conversion during competition, especially from slow and fast-rapid conversion. When the competition is intense, there is an increase in continuous braking and highintensity movements, such as fast starts (12). 
Table 5 Overall fitness of structure model of variable direction ability of badminton players

\begin{tabular}{|c|c|c|c|c|c|c|c|c|c|}
\hline$\chi^{2}$ & \multicolumn{2}{|c|}{ Absolute fitness } & AGFI & \multicolumn{4}{|c|}{ Value-added fitness } & \multicolumn{2}{|c|}{ Parsimonious fitness } \\
\hline$P>0.05$ & $<0.08$ & $>0.9$ & $>0.9$ & $>0.9$ & $>0.9$ & $>0.9$ & $>0.9$ & $<2.00$ & $>0.5$ \\
\hline $19.83 ; P=3.15$ & 0.046 & 0.972 & 0,908 & 0.924 & 0.943 & 0.921 & 0.903 & 1.239 & 0.589 \\
\hline$\sqrt{ }$ & $\sqrt{ }$ & $\sqrt{ }$ & $\sqrt{ }$ & $\sqrt{ }$ & $\sqrt{ }$ & $\sqrt{ }$ & $\sqrt{ }$ & $\sqrt{ }$ & $\sqrt{ }$ \\
\hline
\end{tabular}

Model fitness indicates the degree of fit between the hypothetical model and the actual data. Only when the three fitness degrees meet the standard means that the hypothetical model is well matched with the actual data.

Many previously published studies on the movement speed of lower limbs of badminton players have found that the movement speed of athletes' lower limbs has an impact on their performance.

\section{Coordination affects the atbletic ability of badminton players}

Coordination refers to the ability of coordinated movement of muscle groups related to specific movements under the control of the central nervous system (13). It is the ability of the movements and the muscle groups to work together. Badminton is carried out in the fierce conversion of attack and defense. Coordination is the basis of the conversion of attack and defense. Therefore, coordination is very important for badminton players. Jaworski et al. (14) studied the control ability of badminton players and found that the coordination directly determines the quality of badminton players' movement. There are obvious differences between different levels of players' coordination ability, and highlevel players usually have better coordination ability. The characteristics of badminton determine the high requirements of athletes' coordination ability, which requires faster movement speed, shorter brain reaction time, and the ability to quickly change movements. Studies have found that professional badminton players are higher than judo players and non professional badminton players in coordination ability (15). This demonstrates the decisive role of coordination in sports performance.

\section{Effects of response ability on performance of badminton players}

Reaction time refers to the time interval from stimulation to the beginning of reaction. The length of the reaction time represents the strength of the reaction, and the strength of the reaction represents the level of the athletes to a certain extent. Badminton requires a kind of instantaneous thinking mode, which requires athletes to have strong reaction ability to make judgement in a short time to cope with the unexpected situation on the field. Cao et al. found that the dynamic response time of high-level badminton players was obviously higher than that of low-level athletes, and the level of high-level badminton players in meter running and re-entry running was significantly higher than that of other high-level athletes, indicating that the response time factor is an important factor affecting the ability of badminton players to change direction (16). Mehmet's study of the visual and auditory responses of 15 national players participating in the Inter Milan badminton tournament found that the length of the visual and auditory responses was highly correlated with the performance of the sport. The level of players with short reaction time in smashing, returning and handling the near-net ball was significantly higher than that of the players with long reaction time (17).

Mahesh's study (18) on the response ability of badminton players found that badminton players responded quickly to visual motion signals and had better visual and visual performance. High-level badminton players had faster myoelectric onset and visual motion response, which were related to the slow activation of stimuli in early visual (regional MT) and sports (BA6) regions. They found that both visual perception processing speed and visual movement conversion helped improve the visual performance of badminton players. These findings indicate that badminton training should selectively induce the adaptation of athletes' visual system according to the requirements of sports visual ability, which can improve the response ability of badminton players and enhance the effectiveness of training. Cutsem's study found that the mental fatigue of badminton players affects their visual and auditory response, and the corresponding prolongation of the visual and auditory response when the athletes are mentally tired. At the same time, badminton players 
with short visual and auditory responses have higher psychological stability in the competition, can better control the rhythm of the competition, and play a greater role in their own techniques and tactics (19).

\section{Lower limb explosive power training for badminton players}

The flexibility of lower limbs has a great influence on the starting speed and displacement speed of badminton players. Athletes need to have good lower limb explosive power and flexibility to support and coordinate technical movements (20). Chahal's research (21) on the relationship between lower extremity explosive force and the success rate of smash of 60 badminton players in the Delhi national team found that athletes with strong explosive power of lower limbs have fast and strong ability to smash, so the success rate of smashing is obviously higher than that of athletes with weak explosive power of lower limbs. The success rate of smashing of male athletes is higher than that of female athletes, which is also related to the strong explosive power of lower limbs of male athletes. Lower extremity explosive power not only has an influence on the technical level of badminton players but also on the competitive ability of badminton players. Strong lower extremity explosive power is helpful in improving athletes' competitive ability and then promote the athletes to use skills and tactics in the competition. Koh's research (22) on the impact of explosive power on the overall competitive ability of 34 high-level badminton players in Singapore found that the explosive power of badminton players was closely related to the take-off speed. The athletes with strong lower extremity explosive power have fast takeoff speed and accurate hitting point selection. The fatigue time for the athletes with strong lower extremity explosive force is later than that of the athletes with weak explosive force, indicating that the lower extremity explosive power is related to the speed of physical consumption. The athletes with strong lower extremity explosive force have strong psychological endurance and enough confident in the competition, which is easier for them to win the whole game.

There are many influencing factors of lower extremity explosive force, which mainly include systemic explosive force, trunk explosive force, muscle extension, joint flexibility, speed of pedaling, hip joint strength, lower extremity force level, and coordinated force level (23). Therefore, coaches should strengthen the training related to the lower limb explosive force, so as to improve the lower limb explosive force of badminton players in all directions. In the selection of athletes, the index of lower extremity explosive force must be an important reference factor; only athletes with good lower extremity explosive force can become high-level players.

Coordination of the lower limbs was found to have the highest correlation with variable direction ability (correlation coefficient: 0.91 ) followed by moving speed (correlation coefficient: 0.86). The correlation between reaction and the explosive power of lower limbs and variable direction ability was also significant (correlation coefficient: 0.81 and 0.79 , respectively), indicating that the correlation between the 4 factors and the variable direction ability was high.

In conclusion, this study used SpeedCourt badminton players get to ability, a study to test system through principal component analysis 4 impact factors, respectively is a response to a speed factor, coordinated ability factor, ability factor, lower limbs explosive power factor, and the change of the badminton players to the ability to establish structural equation model, the fit of the model and the measured data is good, variable structure model to the ability theory to obtain the preliminary verification, accord with people's knowledge to the ability to change rule, this model can be used as a training on the basis of variable to the ability of badminton players lay a foundation for the research of badminton players sensitive quality.

Athletes have a complex physical quality, the various qualities overlap, cross, mutual influence, and even antagonistic may, in the study cannot completely separate the relevant qualities, showing that you have me and I have you entangled state, the relationship between the relationship cannot simply be expressed by causality or positive and negative correlation. Therefore, in future studies, we will grasp the principal contradiction, from the system theory, based on the complex network theory, to further study badminton players' ability to change direction.

\section{Acknowledgments}

Funding: None.

\section{Footnote}

Reporting Checklist: The authors have completed the MDAR reporting checklist. Available at http://dx.doi.org/10.21037/ apm-21-644 
Data Sharing Statement: Available at http://dx.doi. org/10.21037/apm-21-644

Conflicts of Interest: Both authors have completed the ICMJE uniform disclosure form (available at http://dx.doi. org/10.21037/apm-21-644). The authors have no conflicts of interest to declare.

Ethical Statement: The authors are accountable for all aspects of the work in ensuring that questions related to the accuracy or integrity of any part of the work are appropriately investigated and resolved. All human trials have been approved by Shanghai Institute of Physical Education and Training (No. 2017047). All procedures performed in this study involving human participants were in accordance with the Declaration of Helsinki (as revised in 2013). Informed consent was taken from all the patients.

Open Access Statement: This is an Open Access article distributed in accordance with the Creative Commons Attribution-NonCommercial-NoDerivs 4.0 International License (CC BY-NC-ND 4.0), which permits the noncommercial replication and distribution of the article with the strict proviso that no changes or edits are made and the original work is properly cited (including links to both the formal publication through the relevant DOI and the license). See: https://creativecommons.org/licenses/by-nc-nd/4.0/.

\section{References}

1. Que N. Measurement index system construction for male teenagers' special physical training in badminton. Journal of Chengdu Sport University 2014;41:91-6.

2. Zhao XT, Ge CL, Sun P. Definition and classification of sport agility. Journal of Wuhan Institute of Physical Education 2012;46:92-5.

3. Phomsoupha M, Laffaye G. Multiple Repeated-Sprint Ability Test With Four Changes of Direction for Badminton Players (Part 2): Predicting Skill Level With Anthropometry, Strength, Shuttlecock, and Displacement Velocity. J Strength Cond Res 2020;34:203-11.

4. Meir R, Newton R, Curtis E, et al. Physical fitness qualities of professional rugby league football players: determination of positional differences. J Strength Cond Res 2001;15:450-8.

5. Düking P, Born DP, Sperlich B. The SpeedCourt: Reliability, Usefulness, and Validity of a New Method to Determine Change-of-Direction Speed. Int J Sports
Physiol Perform 2016;11:130-4.

6. Wu ML, Tu JT. SPSS and Statistical Application Analysis. Northeast University of Finance and Economics Press, 2012:700-1.

7. Stockbrugger BA, Haennel RG. Contributing factors to performance of a medicine ball explosive power test: a comparison between jump and nonjump athletes. $\mathrm{J}$ Strength Cond Res 2003;17:768-74.

8. Wu ML. Structural equation model: operation and application of AMOS. Second edition. Chongqing University Press, 2010:236-7.

9. Sung B, Lee J, Li D. Comparison on Basal Physical Fitness and Badminton Smash Speed of Korea National Badminton Player in Male and Female. Korean Journal of Sport Science 2014;25:364-73.

10. Abdul Hamza M. Relationship explosive power and motor speed of the upper limbs for some attacking skills in Badminton for Iraq's youth team. International Journal of Advanced Sport Sciences Research 2014;2:32-8.

11. Salah W, Zuhair M, Shakir N, et al. Effect of Exercises by Using Multi-Weights Racket in Developing the Force Recognized by Speed and Accurate Crushing Strike for Badmintons Player. International Journal of Advanced Sport Sciences Research 2013;1:164-73.

12. Chen SC. A study on the Special quality of Chinese High-level Badminton Men's Singles players by Multicombination training method. Beijing University of physical Education, 2016.

13. Yang XR. Practical exercise physiology. 2nd edition[M]. Beijing University of physical Education Press 1998:238-9.

14. Jaworski J, Lech G, MichałŻak, et al. The level of selected coordination abilities in badminton players at various ages and sport skill levels as compared to non-athletes. Baltic Journal of Health and Physical Activity 2017;9:33-43.

15. Jaworski J, Lech G, Ambroy T, et al. Profile of coordination motor abilities in elite judokas and badminton players compared to non-athletes. Biomedical Human Kinetics 2020;12:17-24.

16. Cao J, Lu J, Liao JJ. A Summary of the Research on the selection of Badminton players. Hubei Sports Science and Technology 2014;33:607-10.

17. Yüksel MF, Tunç GT. Examining the Reaction Times of International Level Badminton Players Under 15. Sports (Basel) 2018;6:20.

18. Mahesh B, Kalpesh V, Gitesh D, et al. A comparative study of visual reaction time in badminton players and healthy controls. Indian Journal of Applied Basic Medical Sciences 2013;57:76-82. 
19. Cutsem JV, Pauw KD, Vandervaeren C, et al. Mental fatigue impairs visuomotor response time in badminton players and controls. Psychol Sport Exerc 2019;45:101579.

20. Wei YR. Analysis on the present situation of body shape and physique of College Badminton athletes in physical Education Colleges and Universities. Journal of Shaoyang University 2017;14:91-6.

21. Chahal M. Relationship between motor abilities and clear skill level of Delhi badminton players. International Journal of Physical Education, Sports and Health

Cite this article as: $\mathrm{Li} \mathrm{Q}$, Ding $\mathrm{H}$. Construction of the structural equation model of badminton players' variable direction ability and its enlightenment to sports training. Ann Palliat Med 2021;10(4):4623-4631. doi: 10.21037/apm-21-644
2015;2:119-23.

22. Koh M. Lower limb Kinetic characteristics of male developmental athlete runners, soccer and badminton players from the Singapore Sports School. Science and Sports 2014;29:S31-2.

23. Zhang J. Research on Lower limb strength and Stability training of Chinese Elite Juvenile rhythmic gymnasts. Beijing University of physical Education, 2012.

(English Language Editor: R. Scott) 